\title{
A New Verbal Reconstruction Task to Assess the Integrative Function of Long-Term Working Memory
}

M. Hupet, A.-M. Schelstraete, L. Demanet and G. Pourtois

\section{OpenEdition}

\section{Journals}

Electronic version

URL: http://journals.openedition.org/cpl/243

DOI: $10.4000 / \mathrm{cpl} .243$

ISSN: $1379-6100$

Publisher

Centre PsyCLÉ

\section{Printed version}

Date of publication: 1 August 2000

\section{Electronic reference}

M. Hupet, A.-M. Schelstraete, L. Demanet and G. Pourtois, « A New Verbal Reconstruction Task to Assess the Integrative Function of Long-Term Working Memory », Current psychology letters [Online], 2000/2, 2 | 2000, Online since 17 September 2003, connection on 08 September 2020. URL : http:// journals.openedition.org/cpl/243; DOI : https://doi.org/10.4000/cpl.243

This text was automatically generated on 8 September 2020

(c) All rights reserved 


\section{A New Verbal Reconstruction Task to Assess the Integrative Function of Long-Term Working Memory}

M. Hupet, A.-M. Schelstraete, L. Demanet and G. Pourtois 